\title{
Behavioral Changes to Repeated Takeovers in Highly Automated Driving: Effects of the Takeover-Request Design and the Nondriving- Related Task Modality
}

\author{
Fabienne Roche (iD), Technische Universität Berlin, Germany, Anna Somieski, \\ Constin GmbH, Berlin, Germany, and Stefan Brandenburg, Technische \\ Universität Berlin, Germany
}

\begin{abstract}
Objective: We investigated drivers' behavior and subjective experience when repeatedly taking over their vehicles' control depending on the design of the takeover request (TOR) and the modality of the nondriving-related task (NDRT).

Background: Previous research has shown that taking over vehicle control after highly automated driving provides several problems for drivers. There is evidence that the TOR design and the NDRT modality may influence takeover behavior and that driver behavior changes with more experience.

Method: Forty participants were requested to resume control of their simulated vehicle six times. The TOR design (auditory or visual-auditory) and the NDRT modality (auditory or visual) were varied. Drivers' takeover behavior, gaze patterns, and subjective workload were recorded and analyzed.
\end{abstract}

Results: Results suggest that drivers change their behavior to the repeated experience of takeover situations. An auditory TOR leads to safer takeover behavior than a visual-auditory TOR. And with an auditory TOR, the takeover behavior improves with experience. Engaging in the visually demanding NDRT leads to fewer gazes on the road than the auditory NDRT. Participants' fixation duration on the road decreased over the three takeovers with the visually demanding NDRT.

Conclusions: The results imply that (a) drivers change their behavior to repeated takeovers, (b) auditory TOR designs might be preferable over visual-auditory TOR designs, and (c) auditory demanding NDRTs allow drivers to focus more on the driving scene.

Application: The results of the present study can be used to design TORs and determine allowed NDRTs in highly automated driving.

Keywords: auditory displays, driver behavior, eye tracking, human-automation interaction, interface evaluation, vehicle automation, visual displays

Address correspondence to Fabienne Roche, Technische Universität Berlin, Marchstr. 23, Berlin, 10587, Germany; e-mail: f.roche@tu-berlin.de.

\section{HUMAN FACTORS}

Vol. 61, No. 5, August 2019, pp. 839-849

DOI: $10.1177 / 0018720818814963$

Article reuse guidelines: sagepub.com/journals-permissions Copyright (C) 2018, Human Factors and Ergonomics Society.

\section{INTRODUCTION}

Highly automated driving fundamentally changes the driving task. While the system performs the dynamic driving task, the driver shifts from being a controller to being a supervisor (SAE International, 2018). However, the driver remains responsible for his or her vehicles' performance in case of a system failure (SAE level 3, SAE International, 2018). Here, the system presents a takeover request (TOR). These takeovers occur after a period of highly automated driving, when drivers are out-of-the-loop lacking situation awareness (Endsley, 1995; Endsley \& Kiris, 1995; Parasuraman, Sheridan, \& Wickens, 2000). However, before decisions can be made and responses to TORs can be selected, the drivers have to perceive and to process the driving situation and to develop situation awareness (Parasuraman et al., 2000; Yamani $\&$ Horrey, in press). Hence, the takeover of a distracted driver takes longer and is more errorprone than if the driver was aware of the situation (Parasuraman et al., 2000). It can be termed to be ironic that takeovers in highly automated driving, where drivers are most likely distracted, must happen as quickly as possible; wrong decisions may have serious consequences.

Being aware of the driving situation has high potential to speed up information processing. It might also lead to better and safer performance (Endsley, 1995). Situation awareness may be affected by different external factors in addition to the preceding period of automated driving system capability, interface design, stress and workload, and complexity - as well as by individual factors: abilities, experience, and training (Endsley, 1995). In this article, we focus on the influence of three of these aspects on takeover 
behavior and performance: (1) interface design, (2) workload, and (3) experience. We chose to vary these aspects because they are either controllable (interface design) or highly likely to vary in road traffic (workload and experience).

\section{INTERFACE DESIGN}

Interface design manifests in the design of takeover requests in the context of highly automated driving. TORs may be presented auditory, visually, tactilely, or in combination. Driving is mainly a visual task. Based on Wicken's Multiple Resource Theory (Wickens, 2002), a driver's takeover performance should be poorer when the TOR is presented visually compared with an auditory or tactile presentation. That is due to the fact that a visual TOR uses the same (visual) resource as the driving task. Indeed, most studies show that visual TORs are associated with longer takeover times compared with auditory, visual-auditory, or tactile TORs (Naujoks, Mai, \& Neukum, 2014; Politis, Brewster, \& Pollick, 2015a, 2015b). For example, Politis et al. (2015a) compared all possible combinations of auditory, visual, and tactile cues in a simulator. Takeover times were slowest with the visual TOR followed by the tactile TOR. In addition, response accuracy was lowest and lateral deviation was highest with the visual TOR. The remaining combinations did not differ regarding takeover time and lateral deviation. With the visual-auditory TOR, responses were most accurate. In a similar study with language-based and abstract cues, Politis et al. (2015b) again found slowest response times with the visual TOR. In addition, there is evidence that language-based auditory TORs lead to faster and more accurate takeovers than abstract tones (Forster, Naujoks, Neukum, \& Huestegge, 2017; Politis et al., $2015 b)$. For example, Wright et al. (2017) investigated the effects of auditory cue specificity on situation awareness. The results show that environmental cues that were presented auditory lead to an increase in hazard detection in comparison to unspecific or threat cues. This finding indicates that TORs should contain valuable information about the driving environment so that drivers can regain situation awareness more quickly (Wright et al., 2017). To conclude, the drivers' perception of auditory and multimodal TORs is faster and their actions are more accurate than of visual TORs. In addition, language-based auditory TORs are more promising than abstract tones.

\section{WORKLOAD}

In highly automated driving, it is very likely that drivers will engage in nondriving-related tasks (NDRTs; Carsten, Lai, Barnard, Jamson, \& Merat, 2012). In fact, there is strong evidence that takeover performance deteriorates when drivers engage in NDRTs (Feldhütter, Gold, Schneider, \& Bengler, 2017; Radlmayr, Gold, Lorenz, Farid, \& Bengler, 2014; Wandtner, Schömig, \& Schmidt, 2018). Feldhütter et al. (2017) distracted their drivers with the visually demanding surrogate reference task (SuRT; ISO/ TS, 2012) while driving highly automated. The engagement in the NDRT decreased the time-tocollision (TTC), increased the takeover time, and increased the number of gaze switches from the NDRT to the driving scene instead of a constant observation of the driving scene. These findings are in line with Wickens' multiple resources theory (2002) stating that two tasks addressing the same resource modality are processed sequentially. Thus, engaging in a visual NDRT and perceiving and comprehending the driving situation should lead to poorer performance than engaging in an auditory NDRT (Wickens, 2002). Therefore, the modality of the NDRT determines to which extent perceptual resources have to be shared in addition to the presence or absence of a NDRT (cf. Wickens, 2002). Indeed, Radlmayr et al. (2014) observed more collisions with a visual NDRT (SuRT) than with an auditory NDRT (n-back) or no NDRT. However, they did not find a difference between NDRTs on drivers' takeover time, TTC, and longitudinal acceleration behavior. In a study of Wandtner et al. (2018), participants experienced five takeover situations while engaging in different NDRTs. A visual-manual NDRT impaired the takeover performance the most, compared with no, auditoryverbal, or visual-verbal NDRT.

\section{EXPERIENCE}

Drivers of highly automated systems will experience TORs, because the systems may reach their limits once in a while. Prior acquired 
skills, experience, and feedback are crucial for operators of automated systems in case of an automation failure (Bainbridge, 1983; Parasuraman et al., 2000). Hence, experiencing takeover situations repeatedly may heavily influence drivers' situation awareness and, thereby, takeover performance (Endsley, 1995). Presumably, drivers' takeover performance becomes better with increasing experience. However, literature shows that driving behavior becomes riskier over time as trust increases. Hoedemaeker and Brookhuis (1998) report that their participants adapted higher speeds, shorter time headways, and stronger braking behavior when driving with an assistance system for a certain time. Hergeth, Lorenz, Vilimek, and Krems (2016) observed fewer gazes on the driving scene with increasing trust in the highly automated vehicle. To conclude, driving behavior may not improve with experience. It might rather deteriorate as trust in the system increases. Some studies repeatedly exposed their participants to TORs, but with varying time of the highly automated drive preceding the TOR (Feldhütter et al., 2017), varying traffic density (Gold, Körber, Lechner, \& Bengler, 2016), different situational complexity (Damböck, Farid, Tönert, \& Bengler, 2012), or different TOR designs (Petermeijer, Bazilinskyy, Bengler, \& de Winter, 2017; Walch, Lange, Baumann, \& Weber, 2015). Therefore, it is still unclear how takeover behavior changes after repeatedly experiencing similar takeover situations.

\section{Objectives and Hypotheses}

The present study has two objectives. First, it examines the effects of the TOR design (auditory or visual-auditory) and the NDRT modality (auditory or visual), and their interaction on takeover behavior, gaze patterns, and drivers' subjective experience. Second, the study investigates the drivers' behavioral changes to the repeated experience of takeover situations and evaluates whether the changes depend on the TOR design or the NDRT modality. In the context of this study, behavioral changes refer to a difference in the dependent variables between two successive takeovers.

We expect better takeover behavior, more gazes on the street, and lower subjective workload with the auditory TOR compared with the visual-auditory TOR (H1); the same applies to the auditory NDRT compared with the visual NDRT (H2). In addition, best takeover behavior is expected with the auditory TOR combined with the auditory NDRT (H3). Moreover, worst takeover behavior is assumed with the visualauditory TOR in combination with the visual NDRT (H4). These hypotheses are tested onesided. In addition, we expect behavioral changes over the repeated takeover situations with the same NDRT (H5). Finally, we expect a difference over repeated takeover situations depending on the TOR design (H6) and the NDRT modality (H7), respectively. These hypotheses are tested two-sided because literature does not give a clear indication how the repeated experience of takeovers affects takeover behavior, gaze pattern, and subjective workload.

\section{METHOD}

\section{Participants}

Forty participants (20 females) with ages ranging from 22 to 65 years $(M=27$ years, $S D=$ 7 years) took part in the study. They held a valid driving license for an average of 9 years $(S D=$ 7 years). Participants had normal or correctedto-normal vision. Nineteen participants (47\%) reported to have some experience with driver assistance systems such as adaptive cruise control or parking sensors. Ten participants $(25 \%)$ had experience with driving simulator studies. Twenty-two participants $(55 \%)$ reported to have driving experience of less than $5,000 \mathrm{~km}$ per year, $16(40 \%)$ between 5,000 and 20,000 $\mathrm{km}$ per year, and $2(5 \%)$ more than $20,000 \mathrm{~km}$ per year. Participants received credits for their participation. This research complied with the code of ethics of the American Psychological Association.

\section{Materials}

The experiment was conducted in a fixedbased driving simulator, consisting of a vehicle mock-up including an adjustable BMW driver seat, a force feedback steering wheel (Senso Wheel), gas and brake pedals. The vehicle speed in $\mathrm{km} / \mathrm{h}$ and revolutions per minute were shown on a 24-in monitor behind the steering wheel. 


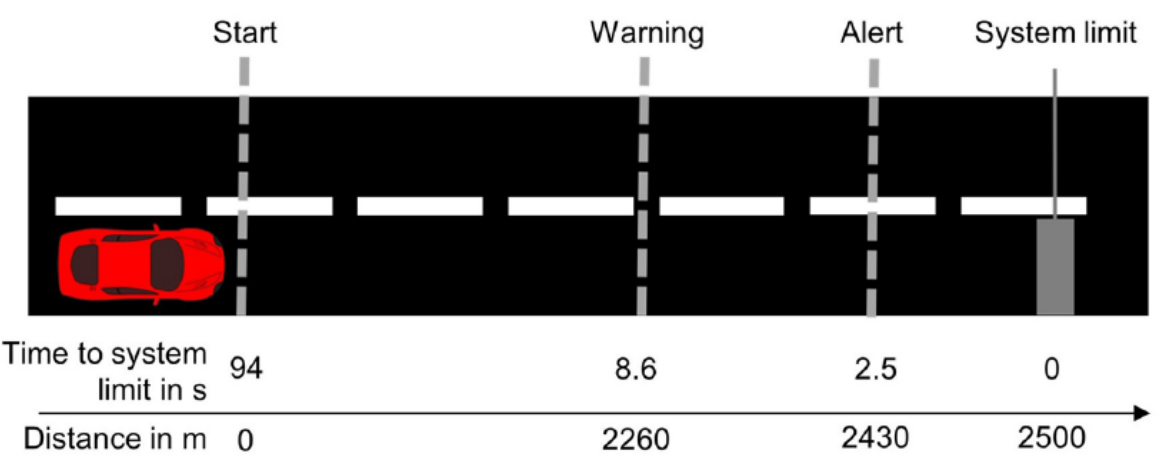

Figure 1. Illustration of the sequence of an experimental trial with the time budget to the system limit and distance from start to the warning, alert, and construction site.

SILAB ${ }^{\mathrm{TM}}$ was used to visualize the driving scene on a rear-projection screen of $2 \times 2 \mathrm{~m}$. This screen was placed about $2.5 \mathrm{~m}$ in front of the vehicle mock-up. The driving scenario was a straight, two-lane rural road of 3,000 m length including trees, mountains, houses, etc. and no traffic on the opposite lane. A construction site was placed after $2,500 \mathrm{~m}$, which became visible after 2,260 m together with the TOR (see Figure 1). The driving scenario was identical for each repetition. Sound included wind and engine noise and was provided by a Yamaha speaker. A tablet PC (Samsung Galaxy Note 10.1, standard factory settings) was mounted on the participants' right-hand side to administer the NDRT.

The takeover request (TOR) consisted of two steps, a warning and an alert. Half of the participants experienced a visual-auditory TOR. The first step, the warning, was a single tone followed by the text, "Warning! Road Works ahead. Take over vehicle control soon!" which was shown in yellow on the projection screen, mimicking a head-up display. It was presented $8.6 \mathrm{~s}$ before reaching the construction site. The second step, the alert, was another single tone followed by the message "Alert! Take over vehicle control now!" which was shown in red on the screen, $2.5 \mathrm{~s}$ before reaching the construction site (see Figure 2 ). These time budgets were chosen based on research showing that a relatively safe takeover period should last longer than $8 \mathrm{~s}$ for distracted drivers (Agrawal, Wright, Samuel, Zilberstein, \& Fisher, 2017; Kuehn, Vogelpohl, \& Vollrath, 2017); $2.5 \mathrm{~s}$ aligned to the minimum time budget used in Zeeb, Buchner, \& Schrauf (2015). The wording and content of the TOR was chosen based on Wright et al. (2017) and Politis et al. (2015a). The other half of the sample experienced an auditory TOR. Here, the warning and alert messages were read out loud to the participants via speakers at the respective points in time. In this case, neither a single tone nor a graphical element was presented.

The nondriving-related task (NDRT) was a questions-and-answers-game, consisting of questions with three response options each (one correct). In the visual condition, question and response options were presented on the tablet PC. Participants selected their answers by tapping on it. In the auditory condition, the experimenter read the questions and the answers out loud and the participants selected one of the answers verbally. To ensure consistency in the auditory condition, both experimenters were of same sex, age, and social background, and both were highly trained. The next question was presented after choosing one of the answers (or a maximum of 20 s) in both conditions. The NDRT served as a distraction from monitoring the environment.

Eye movements were collected via $S M I^{T M}$ eye-tracking glasses, version 2.0 , with a sampling frequency of $60 \mathrm{~Hz}$. In order to determine visual distraction, which was here defined as not monitoring the road, participants' gazes were manually coded with BeGaze version 3.7 to the area of interest: the road or white space.

The NASA Task Load Index (NASA-TLX) was used to evaluate participants' subjective workload (Hart \& Staveland, 1988). We waived the weighting procedure of the subscales because 


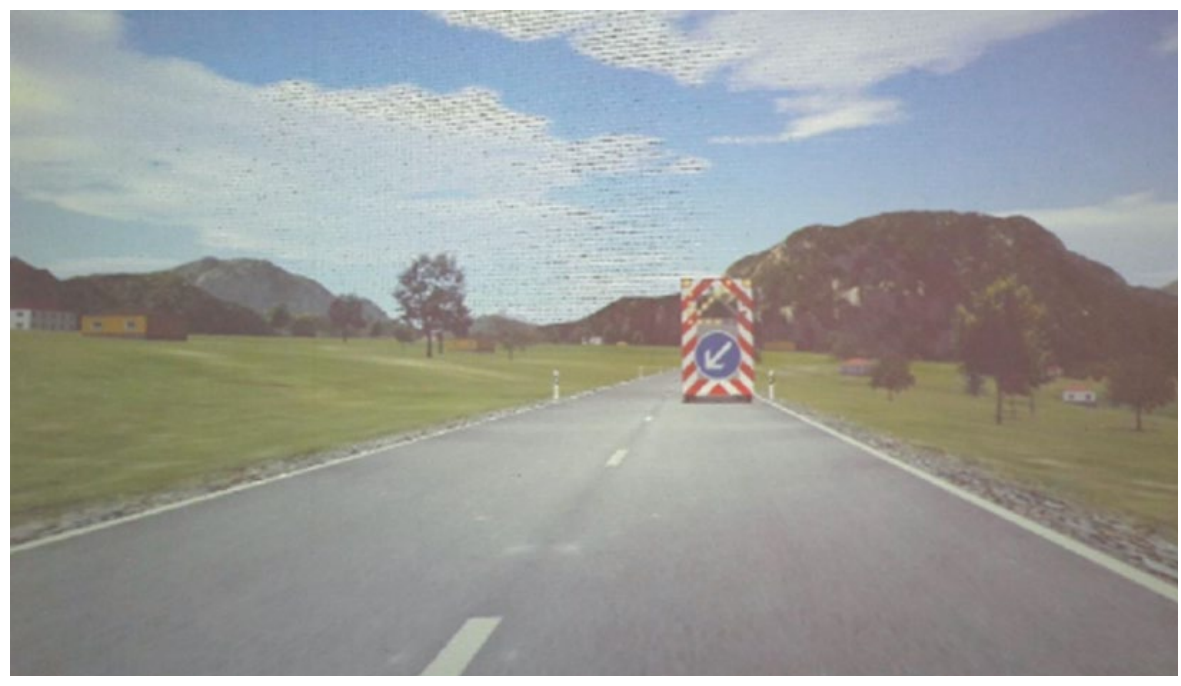

Figure 2. Visualization of the takeover situation in the driving simulator.

it is quicker to apply (Hart, 2006) and has proven to be equally or even more sensitive (Byers, Bittner, \& Hill, 1989; Hendy, Hamilton, \& Landry, 1993). We computed a mean subjective workload score by averaging across the six subscales.

\section{Procedure and Experimental Design}

Participants were welcomed and asked to read the written instructions. Informed consent was obtained from each participant. Then they were informed about the capabilities of the highly-automated driving system. The experimenter explained the NDRT and practiced one question with the participants. The participants manually drove a 2-min practice drive to familiarize themselves with the driving simulator. After the eye-tracking glasses were calibrated, the participants completed their first highly automated drive without a TOR.

For the experimental phase, participants were assigned to one of the two TOR-design conditions. They received a verbal and graphical description of the respective TOR and were instructed to take over vehicle control as fast and safely as possible upon request. Each participant completed a total of six trials; the first three trials were blocked to one NDRT modality and the last three trials blocked to the remaining one. We chose three trials per condition because there is evidence from human-machine-interaction that most behavioral changes occur in the second or third trial (Backhaus \& Brandenburg, 2014; Brandenburg \& Backhaus, 2016). The blocks of NDRT modality were counterbalanced across participants. Therefore, the experimental design was a 2 (TOR design: auditory or visual-auditory, between-subjects) $\times 2$ (NDRT modality: auditory or visual, within-subjects) $\times 3$ (trial, within-subjects) mixed design. Each experimental trial lasted for about 1.5 min starting with the automated acceleration of the participants' vehicle. After automatically achieving the traveling speed of $100 \mathrm{~km} / \mathrm{h}$, participants started to play the questions-and-answers game. A TOR was presented at the end of each trial because the construction site blocked the participants' lane at 2,500 $\mathrm{m}$. The experimental phase was followed by a short interview and a demographic questionnaire. The complete experiment lasted for about $1 \mathrm{hr}$.

Dependent variables included takeover time (TOT) in s, minimum time-to-collision $\left(\mathrm{TTC}_{\min }\right)$ in $\mathrm{s}$, minimum acceleration $\left(a_{\text {min }}\right)$ in $\mathrm{m} / \mathrm{s}^{2}$, standard deviation of lateral position $(S D L P)$, the maximum change of the steering wheel angle $\left(\partial_{\max }\right)$ in degrees, the proportional fixation duration on road in percent, and the subjective workload ratings, which were assessed after each trial. Fixation duration is supposed to be a significant indicator of peoples' attention and their allocation of resources. Higher fixation durations are associated with a higher probability of 
conscious information processing (Chen \& Choi, 2008). Short TOTs, long $\mathrm{TTC}_{\text {min }}$, small $a_{\text {min }}$, small steering wheel angle changes, and a large portion of fixation duration are defined as less critical and better takeover behavior. The input thresholds were set to $-0.5^{\circ}$ and $1.4^{\circ}$ of steering wheel angle, $9.2 \%$ of brake pedal position, and $3.2 \%$ of gas pedal position, similar to Gold et al. (2016). As soon as one of these thresholds was exceeded, input was considered to be deliberate, takeover time was measured, and takeover behavior was assessed. We divided the complete takeover situation into two analysis intervals (interval between warning and alert and interval between alert and construction site) because defining various intervals of analysis allows for a fine-grained examination of drivers' behavioral change at different points of the process of resuming their vehicles' control. A third analysis interval was added for drivers' gaze patterns, the $30 \mathrm{~s}$ before the warning. Pretests suggested that drivers gaze behavior prior to a TOR seems to be represented well by their gaze behavior in the last $30 \mathrm{~s}$ of that interval.

\section{RESULTS}

Data analysis followed two steps. First, we screened the data for measurement errors. Two single data points in steering wheel angle were unreasonably high and not in relation to data points, which were measured milliseconds earlier or later. These data points were excluded from the analysis. Second, to test the hypotheses, we computed a series of 2 (TOR design) $\times$ 2 (NDRT modality) $\times 3$ (trial) analyses of variance (ANOVAs) for each dependent variable using RStudio (version 1.0.143). The sphericity assumption for the factor trial was tested using Mauchly Test. If necessary, degrees of freedom were corrected using the Greenhouse-Geisser correction method. In addition, degrees of freedom vary due to missing driving simulator and eye-tracking data. The Bonferroni method was utilized to correct the alpha-level to control for post-hoc comparisons. Effect sizes are reported using $\eta_{\text {partial }}^{2}$ (Lakens, 2013) with $\eta_{\text {partial }}^{2}<.06$ indicating small effects, $\eta_{\text {partial }}^{2}$ between .06 and .14 medium effects, and $\eta_{\text {partial }}^{2}>.14$ large effects (Cohen, 1988). The results are presented separately for the main effects of the TOR design and the NDRT modality and the main effect and interactions of the repeated experience of the takeover situations.

Due to missing data, driving data from 36 participants (17 women, 16 with the auditory TOR, 18 with the auditory NDRT) completing six takeover situations were analyzed, resulting in 216 trials. In each trial, participants answered between 5 and 16 questions of the NDRT ( $M=$ $9.5, S D=0.56)$. On average, $50 \%$ of the questions were correctly answered (Min $=0 \%, \operatorname{Max}$ $=89 \%)$. In 171 trials $(79 \%, 87$ with the auditory TOR, 85 with the auditory NDRT), participants reacted before the alert, the remaining (21\%) reacted after the alert. This resulted in 171 data points in the first analysis interval and 216 trials in the second analysis interval. For a more detailed analysis of the takeovers, see Epple, Roche, and Brandenburg (2018). Even though all participants took over control, in fourteen trials $(6.5 \%)$, participants collided with the construction site or drifted from the road. Four crashes took place with the auditory TOR, nine with the auditory NDRT. Eye tracking data could be analyzed from 33 participants (15 in the auditory TOR group). Subjective data could be analyzed from all 40 participants.

\section{The Effects of the Takeover Request Design}

The TOR design (auditory or visual-auditory) affected all dependent variables except minimal acceleration, fixation duration, and subjective workload (see Table 1 for detailed results). Experiencing the visual-auditory TOR led to significantly longer TOTs and smaller TTCs compared with the auditory TOR. Similarly, between the alert and the construction site, participants in the visual-auditory TOR group showed stronger reactions regarding SDLP and changes in steering wheel angle.

\section{The Effects of the Nondriving-Related Task Modality}

The modality of the NDRT (auditory or visual) affected drivers' SDLP and gaze behavior (see Table 2 for detailed results). The visual NDRT group showed smaller SDLP than the auditory group between warning and alert, whereas the mean SDLP of the auditory NDRT 
TABLE 1: Effects of the Takeover Request (TOR) Design on Takeover Behavior and Workload Ratings

\begin{tabular}{|c|c|c|c|c|c|}
\hline \multirow[b]{2}{*}{ Measure } & \multicolumn{2}{|c|}{ TOR design $M(S D)$} & \multirow[b]{2}{*}{$F^{1}$} & \multirow[b]{2}{*}{$p$} & \multirow[b]{2}{*}{$\eta_{\text {partial }}^{2}$} \\
\hline & Auditory & Visual-auditory & & & \\
\hline TOT & 3.24 s (1.59) & $4.61 \mathrm{~s}(1.84)$ & 7.49 & .010 & .18 \\
\hline $\mathrm{TTC}_{\min }$ & $.98 \mathrm{~s}(0.44)$ & $.59 \mathrm{~s}(0.44)$ & 10.66 & .002 & .24 \\
\hline$\partial_{\max }\left(2^{\text {nd }}\right.$ interval $)$ & $11.52^{\circ}(15.68)$ & $22.51^{\circ}(20.25)$ & 7.57 & .009 & .18 \\
\hline SDLP ( $2^{\text {nd }}$ interval) & $.42(.29)$ & $.68(.75)$ & 6.96 & .012 & .17 \\
\hline
\end{tabular}

Note. TOT $=$ takeover time, $\mathrm{TTC}_{\min }=$ minimum time-to-collision, $\partial_{\max }=$ maximum steering wheel angle change, SDLP = standard deviation of lateral position; $2^{\text {nd }}$ interval refers to the analysis interval between alert and construction site.

${ }^{1} \mathrm{df}(1,34)$.

TABLE 2: Effects of the Nondriving-Related Task (NDRT) Modality on Driving Behavior and Gaze Behavior

\begin{tabular}{|c|c|c|c|c|c|c|}
\hline \multirow[b]{2}{*}{ Measure } & \multicolumn{2}{|c|}{ NDRT modality M (SD) } & \multirow[b]{2}{*}{$F$} & \multirow[b]{2}{*}{$d f$} & \multirow[b]{2}{*}{$p$} & \multirow[b]{2}{*}{$\eta_{\text {partial }}^{2}$} \\
\hline & Auditory & Visual & & & & \\
\hline SDLP ( $1^{\text {st }}$ interval) & $.47(.37)$ & $.37(.32)$ & $6.05^{1}$ & $(1,19)$ & .024 & .24 \\
\hline SDLP (2 ${ }^{\text {nd }}$ interval) & $.47(.30)$ & $.66(.80)$ & $5.67^{2}$ & $(1,34)$ & .023 & .14 \\
\hline $\begin{array}{l}\text { fixation duration ( } 30 \text { s prior } \\
\text { to the warning) }\end{array}$ & $74.78 \%(26.41)$ & $8.51 \%(21.37)$ & $80.89^{3}$ & $(1,32)$ & $<.001$ & .72 \\
\hline fixation duration ( $1^{\text {st }}$ interval) & $88.29 \%(14.91)$ & $64.63 \%(26.71)$ & $33.77^{4}$ & $(1,31)$ & $<.001$ & .52 \\
\hline
\end{tabular}

Note. SDLP = standard deviation of lateral position. $1^{\text {st }}$ interval refers to the analysis interval between the warning and the alert. $2^{\text {nd }}$ interval refers to the analysis interval between alert and construction site.

group remained constant in both analysis intervals. However, the visual NDRT group had larger SDLP than the auditory group between the alert and the construction site.

Participants performing a visual NDRT fixated the road less during the $30 \mathrm{~s}$ prior to the warning and between warning and alert compared with the auditory task group. The gaze behavior of both groups did not differ between alert and construction site in the groups.

\section{The Effects of the Repeated Experience of Takeovers}

We calculated a one-way ANOVA over all six takeovers to check whether the effect of the repeated experience of various takeovers was due to the fact that drivers became familiar with the driving simulator or driving task. The analysis revealed that neither driving behavior nor gaze patterns changed over all six takeover situations.
However, NASA-TLX ratings differed between the six takeovers, $F(3.19,124.41)=8.69, p<.001$, $\eta_{\text {partial }}^{2}=.18$. Post-hoc tests revealed that the ratings in trial 1 were significantly higher than in trial 3, 5, and 6 and ratings in trial 2 were higher than in trial 6, all $p<.0001$ (see Figure 3).

In addition, we observed a two-way interaction of trial and TOR design for $\mathrm{TTC}_{\min }$. $\mathrm{TTC}_{\text {min }}$ increased with the auditory TOR over the three takeover situations but remained at the same level with the visual-auditory TOR, $F(2,68)=$ $5.17, p=.008, \eta_{\text {partial }}^{2}=.13$. $\mathrm{TTC}_{\text {min }}$ was significantly higher in the third takeover situation with the auditory TOR than in any takeover situation with the visual-auditory TOR, all $p<.001$, see Figure 4 left.

A two-way interaction of trial and NDRT modality was found for fixation duration between the warning and the alert, $F(2,62)=4.36, p=.017$, $\eta_{\text {partial }}^{2}=.12$. Figure 4 right illustrates that 


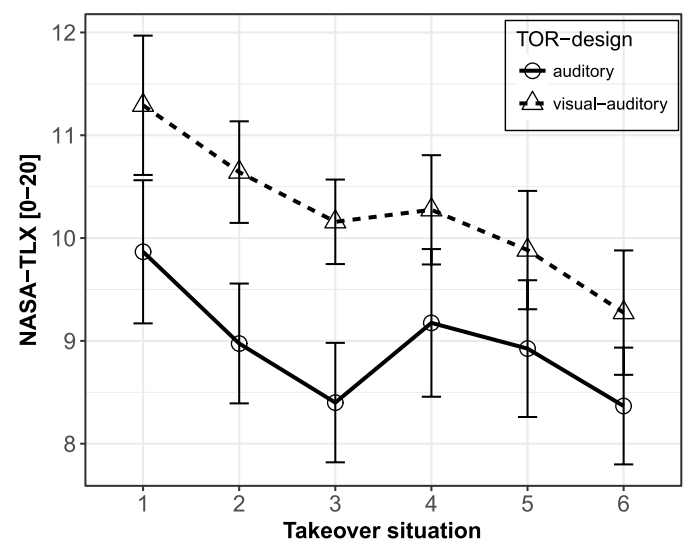

Figure 3. NASA-TLX ratings surveyed after each of the six takeover situations. Participants experienced either the auditory or the visual-auditory takeover request. Consider that the NDRT switched after the $3^{\text {rd }}$ takeover situation. Error bars represent $95 \%$ confidence intervals.

fixation duration on the road decreased over the three takeover situations when engaging in the visual NDRT, whereas drivers' fixation duration remained fairly constant when engaging in an auditory NDRT. Post-hoc test revealed no significant difference between the NDRT modalities and trials and no three-way interaction.

\section{DISCUSSION}

The present study had two objectives. First, it examined the effects of the TOR design (auditory or visual-auditory) and the NDRT modality (auditory or visual) on driver behavior and their experience of the situation. Second, the study investigated the drivers' behavioral changes to the repeated experience of takeover situations and evaluated this effect depending on the TOR design or the NDRT modality. Drivers' takeover behavior and gaze patterns prior and during the process of resuming control were assessed, and subjective workload ratings after each takeover situation were surveyed.

Participants with the auditory TOR took over faster and also showed longer TTCs, and softer steering and braking behavior (H1). These results were predicted by Wickens' Multiple Resources Theory (Wickens, 2002) and in line with studies from Forster et al. (2017) and Politis et al. (2015a), who found shorter takeover times for each TOR that included language-based auditory cues. Accordingly, subjective workload was lower with the auditory than with the visual-auditory TOR (H1). The SDLP was higher with the visual-auditory TOR after the second TOR-step than with the auditory TOR. It could be possible that in trials with the visual-auditory TOR, participants started their lane change maneuver later than participants with the auditory TOR. Indeed, in only $23 \%$ of trials with the visual-auditory TOR, participants changed lane before the second TOR-step, whereas in $54 \%$ of the trials with the auditory TOR, participants changed lane before the second TOR-step. With the visual-auditory TOR, participants might have needed more time to develop situation awareness and to select an action. These results indicate the benefit of auditory TORs in contrast to visual-auditory TORs.

The number of answered questions of the NDRT showed that participants engaged in the task to a certain extent. In addition, in trials with the visual NDRT, participants observed the driving situation less than those with the auditory NDRT $30 \mathrm{~s}$ prior to the warning and between the warning and the alert (H2). Even though participants with the auditory NDRT spent more time looking at the road between the warning and the alert, their SDLP was larger than of those with the visual task. This might be due to the fact that they already started their lane-change maneuver. Indeed, a bigger portion of participants with the auditory NDRT (46\%) who took over control in that first interval started changing lane. Fewer participants (31\%) with the visual task who took over control between warning and alert changed lanes before the alert. This may be related to the fact that changing lanes and verbally answering questions can be accomplished simultaneously since driving is mainly a visual-motor task. With the visual NDRT, participants had to share their attention between two visual-motor tasks: driving and reading on the tablet. Therefore, it is likely that it took those participants longer to develop situation awareness (Endsley, 1995). In the analysis interval between the alert and construction site, gaze behavior did not differ between the conditions, but SDLP was higher for the visual NDRT group. More participants with the visual task started their lane-change maneuver at that point, whereas the auditory-task group 

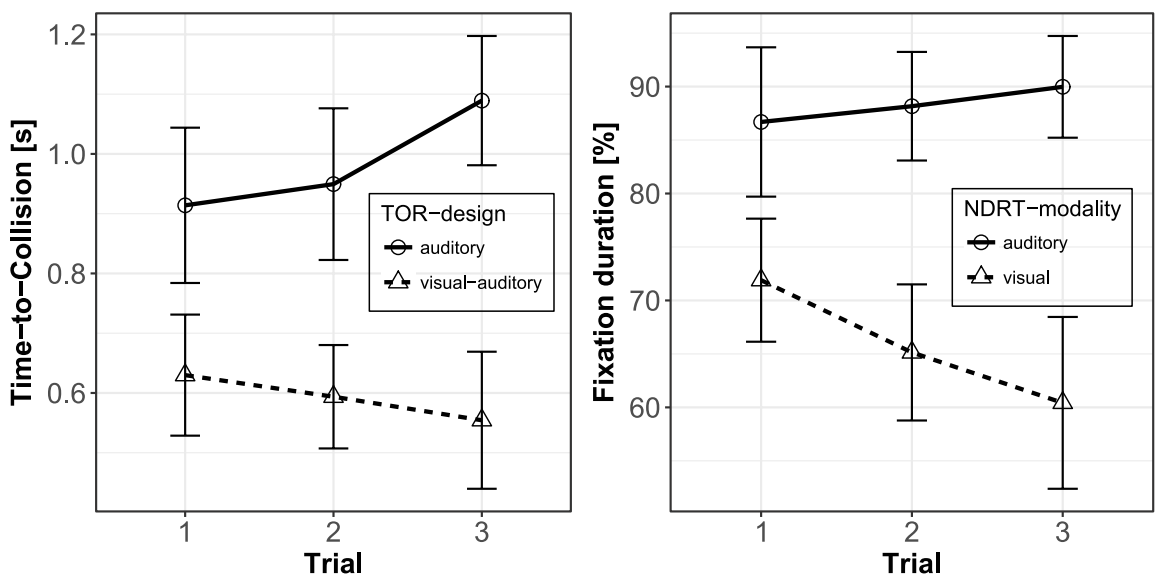

Figure 4. Left: Minimum TTC in s for the three takeovers with the auditory and visualauditory takeover requests (TOR). Right: Fixation duration on road in percent for the three takeovers while engaging in the auditory or visual NDRT between first and second TOR-step. Error bars represent 95\% confidence intervals.

had already completed their lane change. These results suggest that the auditory NDRT is less intrusive than visual, because gazes on the road are important to develop situation awareness, and early reaction enables a safe managing of a critical driving situation. These results give a first implication that visual NDRTs might be critical during highly automated driving.

Subjective workload decreased over all six takeover situations experienced by the participant. This result leads to the assumption that the participants became more familiar with the driving simulator or the takeover situations over the six takeovers. However, takeover behavior did not change over the six repetitions.

The results revealed that repeatedly experiencing three takeover situations with an auditory TOR lengthens the minimum TTC, leading to less critical situations, whereas the TTC with a visual-auditory TOR remained constant over trials (H6). This is partially in line with Wickens' Multiple Resources Theory (Wickens, 2002), that predicts better performance when the perception and processing of information require different modalities, here the auditory TOR and the visual driving situation. These results also imply that takeover behavior becomes safer with the verbal auditory TOR, at least for three repetitions.

Fixation duration on the road remained the same with the auditory NDRT, but decreased over the three takeovers between the warning and alert when participants engaged in the visual NDRT (H7). Participants kept focusing on the visual NDRT, even though the warning was already presented. This is a risky behavior, because they miss time to develop situation awareness. These results imply that gaze behavior becomes riskier with a visual NDRT within three repetitions only.

\section{Limitations}

Three limitations of the present driving simulator study should be mentioned. First, the study did not include oncoming traffic, which might hamper the generalizability of the results. Previous studies presented traffic on the opposite or neighboring lane (Gold et al., 2016; Radlmayr et al., 2014). For example, Gold et al. (2016) found that the drivers' takeover performance was influenced by the number of vehicles on the neighboring lane.

Second, the alert might have been given too short $(2.5 \mathrm{~s})$ prior to the construction site. Therefore, the auditory TOR could not be presented in its full length (4.75 s) before passing the construction site. This situation was created unintentionally. However, results suggest that this aspect did not negatively affect the behavior upon the auditory TOR. In fact, it is likely that more positive effects of the auditory TOR would have been found if it were presented in its full length. 
Third, in each trial, the TOR and construction site were presented at the same position of the simulated track. It could be argued that participants realized this linearity and remembered the position of the construction site. Eventually, they could have expected being requested to takeover, which may have intensified behavioral changes. Therefore, the behavioral changes in real traffic conditions might be even smaller than those found in this study.

\section{CONCLUSION AND FINAL REMARKS}

These results suggest that the auditory TOR leads to better takeover behavior than the visualauditory TOR. In addition, engaging in the auditory NDRT impeded the takeover behavior less than the visual NDRT. This evidence should be considered when designing driver-vehicle interfaces and determining which NDRTs should be permitted while driving highly automated.

\section{ACKNOWLEDGMENT}

We thank Hoai Anh Nguyen for the careful data collection.

\section{KEY POINTS}

- In a driving simulator, 40 participants experienced six takeover situations with either an auditory or visual-auditory takeover request while engaging in an auditory or visually demanding nondrivingrelated task.

- Over the three exposures, takeover behavior improved with the auditory takeover request and the observation of the driving scene deteriorated when engaging in a visual nondriving-related task.

- Takeover behavior and subjective workload was better/lower with the auditory than with the visualauditory takeover request.

- Steering behavior, observation behavior, and subjective workload were better with the auditory nondriving-related task than with the visual one.

\section{ORCID iD}

Fabienne Roche (iD https://orcid.org/0000-00034875-8622

\section{SUPPLEMENTAL MATERIAL}

Supplemental material for this article is available with the manuscript on the $H F$ website.

\section{REFERENCES}

Agrawal, R., Wright, T. J., Samuel, S., Zilberstein, S., \& Fisher, D. L. (2017). Effects of a change in environment on the minimum time to situation awareness in transfer of control scenarios. Transportation Research Record, 2663(1), 126-133. https:// doi.org/10.3141/2663-16

Backhaus, N., \& Brandenburg, S. (2014). Temporal dynamics of emotional activation in man-machine interaction. $i$-com, 13(1), 63-69. https://doi.org/10.1515/icom-2014-0009

Bainbridge, L. (1983). Ironies of automation. Automatica, 19(6), 775-779. https://doi.org/10.1016/0005-1098(83)90046-8

Brandenburg, S., \& Backhaus, N. (2016). The dynamics of filminduced affect and its effect on the interaction with tablet PCs. Behaviour \& Information Technology, 35(5), 410-421. https:// doi.org/10.1080/0144929X.2016.1151076

Byers, J. C., Bittner, A. C., \& Hill, S. G. (1989). Traditional and raw task load index (TLX) correlations: Are paired comparisons necessary? Advances in Industrial Ergonomics and Safety, 481-485.

Carsten, O., Lai, F. C. H., Barnard, Y., Jamson, A. H., \& Merat, N. (2012). Control task substitution in semiautomated driving: Does it matter what aspects are automated? Human Factors: The Journal of the Human Factors and Ergonomics Society, 54(5), 747-761. https://doi.org/10.1177/0018720812460246

Chen, K., \& Choi, H. J. (2008). Visual attention and eye movements, 1-14. Retrieved from https://www.ics.uci.edu/ majumder/ vispercep/paper08/visualattention.pdf

Cohen, J. (1988). Statistical power analysis for the behavioral sciences (2nd ed.). Hillsdale, NJ: Lawrence Erlbaum Associates.

Damböck, D., Farid, M., Tönert, L., \& Bengler, K. (2012). Übernahmezeiten beim hochautomatisierten Fahren [Takeover times for highly automated driving]. In Tagung Fahrerassistenz (p. 16). München.

Endsley, M. R. (1995). Toward a theory of situation awareness in dynamic systems. Human Factors: The Journal of the Human Factors and Ergonomics Society, 37(1), 32-64.

Endsley, M. R., \& Kiris, E. O. (1995). The out-of-the-loop performance problem and level of control in automation. Human Factors: The Journal of the Human Factors and Ergonomics Society, 37(2), 381-394. https://doi.org/ 10.1518/001872095779064555

Epple, S., Roche, F., \& Brandenburg, S. (2018). The sooner the better: Drivers' reactions to two-step take-over requests in highly automated driving. In Proceedings of the Human Factors and Ergonomics Society Annual Meeting, 62(1), 1883-1887.

Feldhütter, A., Gold, C., Schneider, S., \& Bengler, K. (2017). How the duration of automated driving influences take-over performance and gaze behavior. In C. M. Schlick, S. Duckwitz, F. Flemisch, M. Frenz, S. Kuz, A. Mertens, \& S. MützeNiewöhner (Eds.), Advances in ergonomic design of systems, products and processes (pp. 309-318). Berlin, Heidelberg: Springer Berlin Heidelberg. https://doi.org/10.1007/978-3662-53305-5_22

Forster, Y., Naujoks, F., Neukum, A., \& Huestegge, L. (2017). Driver compliance to take-over requests with different auditory outputs in conditional automation. Accident Analysis \& Prevention, 109, 18-28. https://doi.org/10.1016/j.aap.2017.09.019

Gold, C., Körber, M., Lechner, D., \& Bengler, K. (2016). Taking over control from highly automated vehicles in complex traffic situations: The role of traffic density. Human Factors, 58(4), 642-652. 
Hart, S. G. (2006). Nasa-Task Load Index (NASA-TLX); 20 Years Later. Proceedings of the Human Factors and Ergonomics Society Annual Meeting, 50(9), 904-908.

Hart, S. G., \& Staveland, L. E. (1988). Development of NASA-TLX (Task Load Index): Results of empirical and theoretical research. In P. Hancock \& N. Meshkati (Eds.), Human Mental Workload (pp. 139-183). Amsterdam: Elsevier. Retrieved from http:// linkinghub.elsevier.com/retrieve/pii/S0166411508623869

Hendy, K. C., Hamilton, K. M., \& Landry, L. N. (1993). Measuring subjective workload: When is one scale better than many? Human Factors, 35(4), 579-601.

Hergeth, S., Lorenz, L., Vilimek, R., \& Krems, J. F. (2016). Keep your scanners peeled: Gaze behavior as a measure of automation trust during highly automated driving. Human Factors: The Journal of the Human Factors and Ergonomics Society, 58(3), 509-519. https://doi.org/10.1177/0018720815625744

Hoedemaeker, M., \& Brookhuis, K. A. (1998). Behavioural adaptation to driving with an adaptive cruise control (ACC). Transportation Research Part F: Traffic Psychology and Behaviour, 1(2), 95-106. https://doi.org/10.1016/S1369-8478(98)00008-4

ISO/TS. ISO/TS, $14198 \S$ (2012).

Kuehn, M., Vogelpohl, T., \& Vollrath, M. (2017). Takeover times in highly automated driving (Level 3; paper 17-0027). Washington, DC: National Highway Traffic Safety Administration.

Lakens, D. (2013). Calculating and reporting effect sizes to facilitate cumulative science: A practical primer for $t$-tests and ANOVAs. Frontiers in Psychology, 4. https://doi.org/10.3389/ fpsyg.2013.00863

Naujoks, F., Mai, C., \& Neukum, A. (2014, July). The effect of urgency of take-over requests during highly automated driving under distraction conditions. In Proceedings of the $5^{\text {th }}$ International Conference on Applied Human Factors and Ergonomics. Krakow.

Parasuraman, R., Sheridan, T. B., \& Wickens, C. D. (2000). A model for types and levels of human interaction with automation. Systems, Man and Cybernetics, Part A: Systems and Humans, IEEE Transactions On, 30(3), 286-297.

Petermeijer, S., Bazilinskyy, P., Bengler, K., \& de Winter, J. (2017). Take-over again: Investigating multimodal and directional TORs to get the driver back into the loop. Applied Ergonomics, 62, 204-215. https://doi.org/10.1016/j.apergo.2017.02.023

Politis, I., Brewster, S., \& Pollick, F. (2015a). Language-based multimodal displays for the handover of control in autonomous cars. In Proceedings of the 7th International Conference on Automotive User Interfaces and Interactive Vehicular Applications (pp. 3-10). Nottingham: ACM Press. https://doi. org/10.1145/2799250.2799262

Politis, I., Brewster, S., \& Pollick, F. (2015b). To beep or not to beep? Comparing abstract versus language-based multimodal driver displays. In Proceedings of the 33rd Annual ACM Conference on Human Factors in Computing Systems (pp. 3971-3980). Seoul, Korea: ACM Press. https://doi. org/10.1145/2702123.2702167

Radlmayr, J., Gold, C., Lorenz, L., Farid, M., \& Bengler, K. (2014). How traffic situations and non-driving related tasks affect the take-over quality in highly automated driving. Proceedings of the Human Factors and Ergonomics Society Annual Meeting, 58(1), 2063-2067. https://doi.org/10.1177/1541931214581434
SAE International. (2018). Taxonomy and definitions for terms related to driving automation systems for on-road motor vehicles (J3016).

Walch, M., Lange, K., Baumann, M., \& Weber, M. (2015). Autonomous driving: Investigating the feasibility of car-driver handover assistance. In Proceedings of the 7th International Conference on Automotive User Interfaces and Interactive Vehicular Applications (pp. 11-18). Nottingham: ACM Press. https://doi.org/10.1145/2799250.2799268

Wandtner, B., Schömig, N., \& Schmidt, G. (2018). Effects of non-driving related task modalities on takeover performance in highly automated driving. Human Factors: The Journal of the Human Factors and Ergonomics Society, 60(6), 870-881. https://doi.org/10.1177/0018720818768199

Wickens, C. D. (2002). Multiple resources and performance prediction. Theoretical Issues in Ergonomics Science, 3(2), 159177. https://doi.org/10.1080/14639220210123806

Wright, T. J., Agrawal, R., Samuel, S., Wang, Y., Zilberstein, S., \& Fisher, D. L. (2017). Effects of alert cue specificity on situation awareness in transfer of control in Level 3 automation. Transportation Research Record: Journal of the Transportation Research Board, 2663, 27-33.

Yamani, Y., \& Horrey, W. J. (2018). A theoretical model of humanautomation interaction grounded in resource allocation policy during automated driving. Journal of Human Factors and Ergonomics, 5(3), 225-239.

Zeeb, K., Buchner, A., \& Schrauf, M. (2015). What determines the take-over time? An integrated model approach of driver takeover after automated driving. Accident Analysis \& Prevention, 78, 212-221. https://doi.org/10.1016/j.aap.2015.02.023

Fabienne Roche studied psychology at Universität Würzburg and human factors at Technische Universität Berlin, Germany. She obtained her MSc at Technische Universität in 2015, and in July 2017, she began working as a research associate at the department of psychology and ergonomics at Technische Universität Berlin, Germany.

Anna Somieski studied cognitive science at Universität Osnabrück and human factors at Technische Universität Berlin, Germany. She obtained her MSc at Technische Universität in 2017.

Stefan Brandenburg (PhD in 2014) studied psychology and philosophy at Technische Universität Chemnitz, Germany. In May 2008, he became a research associate at the department of psychology and ergonomics at the Technische Universität Berlin.

Date received: June 27, 2018

Date accepted: October 30, 2018 